\title{
PENGARUH KEPUASAN MUZAKKI, TRANSPARANSI DAN AKUNTABILITAS PADA LEMBAGA AMIL ZAKAT TERHADAP LOYALITAS MUZAKKI
}

(Studi Persepsi Pada LAZ Rumah Zakat)

\author{
Indri Yuliafitri, Asma Nur Khoiriyah
}

Universitas Padjadjaran

\begin{abstract}
Abstrak. Pengaruh Kepuasan Muzakki, Transparansi dan Akuntabilitas Pada Lembaga Amil Zakat Terhadap Loyalitas Muzakki (Studi Persepsi Pada LAZ Rumah Zakat). Penelitian ini bertujuan untuk menganalisis pengaruh masing-masing variabel yaitu kepuasan muzakki, transparansi dan akuntabilitas pada Lembaga Amil Zakat terhadap loyalitas muzakki. Sebagai organisasi nonprofit, Lembaga Amil Zakat perlu memerhatikan kepuasan para muzakki, transparansi dan akuntabilitas lembaganya untuk meningkatkan loyalitas muzakki. Dalam penelitian ini data dikumpulkan melalui kuesioner dengan accidental sampling. Responden pada penelitian ini adalah muzakki atau orang yang membayarkan zakat melalui LAZ Rumah Zakat. Teknik analisis yang digunakan adalah analisis regersi linear berganda.

Hasil penelitian ini menunjukkan bahwa kedua variabel independen yaitu kepuasan muzakki dan transparansi mempunyai pengaruh yang positif terhadap loyalitas muzakki.Artinya semakin tinggi kepuasan muzakki dan transparansi lembaga maka semakin tinggi pula loyalitas muzakki. Sedangkan variabel independen akuntabilitas tidak memiliki pengaruh terhadap loyalitas muzakki.
\end{abstract}

Kata Kunci: kepuasan, transparansi, akuntabilitas, loyalitas, lembaga amil zakat.

Abstract. The Influence of Muzakki Satisfaction, Transparency and Accountability in the Amil Zakat Institution toward Loyalty Muzakki (Perception Study on LAZ Rumah Zakat). This study aimed to analyze the effect of each variable that Muzakki satisfaction, transparency and accountability in the Amil Zakat Institution toward loyalty Muzakki. As a nonprofit organization, Lembaga Amil Zakat needs to pay attention the Muzakki satisfaction, transparency and accountability of institutions to increase loyalty Muzakki. In this study, data were collected through a questionnaire with accidental sampling. Respondents in this study were Muzakki or person paying zakat through LAZ Rumah Zakat. The analysis multiple linear regression technique used to solve it. The results showed that both independent variables are Muzakki satisfaction and transparency has positive influence on loyalty Muzakki. This means that the more high satisfaction Muzakki and transparency of the institution, the more high loyalty of Muzakki. On the other hand, the accountability of independent variables have no influence on loyalty Muzakki.

Keywords: Satisfaction, Transparency, Accountability, loyalty, the amil zakat Institution. 


\section{Pendahuluan}

Masalah kemiskinan selalu menjadi masalah yang tak kunjung usai sejak berabad-abad tahun yang lalu. Sejak zaman dahulu, manusia selalu terbagi menjadi kaum kaya miskin, penindas tertindas, penguasa dikuasai.Berbagai upaya untuk mendistribusikan kekayaan telah dilakukan pada setiap peradaban. Namun upaya ini acapkali tidak membuahkan hasil yang signifikan. Ketika Islam hadir, maka mulai dikenal istilah zakat yang merupakan salah satu instrumen keuangan yang berfungsi untuk mengurangi jurang perbedaan antara orang-orang kaya dan miskin.

Berdasarkan data Badan Pusat Statistik Indonesia pada tahun 2010, total penduduk muslim Indonesia mencapai $87,18 \%$ dari 237.641 .432 jiwa atau sekitar 207 juta jiwa (Kementerian Agama, 2012). Kondisi tersebut mencerminkan bahwa Indonesia memiliki potensi zakat yang sangat besar dikarenakan mayoritas penduduknya beragama Islam.

Hasil riset Baznas dan Fakultas Ekonomi dan Manajemen Institut Pertanian Bogor (FEM IPB) pada tahun 2011 menunjukkan bahwa potensi zakat nasional mencapai angka 3,40\% dari PDB, atau sekitar Rp 217 triliun. Namun, dana zakat yang dapat dihimpun oleh BAZNAS dan Lembaga Amil Zakat (LAZ) masih sangat rendah, yaitu baru 1\% dari potensi yang ada, atau sekitar Rp 2,6 triliun (Majalah Zakat edisi Mei-Juni 2013).

Dari hasil riset tersebut dapat dilihat bahwa masih ada 99\% potensi zakat nasional yang belum terserap oleh lembaga pengelola zakat.BAZNAS dan LAZ sebagai lembaga pengelola zakat harus terus berusaha keras untuk meningkatkan penerimaan zakat nasional.Peningkatan jumlah muzakki harus menjadi perhatian utama, namun LAZ juga harus berupaya keras untuk mempertahankan para muzakki yang telah membayar zakatnya melalui Lembaga Amil Zakat (LAZ).

Para muzakki yang telah membayar zakatnya melalui Lembaga Amil Zakat (LAZ) harus sangat diperhatikan, karena muzakki tersebut memiliki pengaruh yang besar bagi LAZ. Muzakki yang terus menerus membayar zakatnya melalui Lembaga Amil Zakat (LAZ) akan berpengaruh pada peningkatan penerimaan zakat lembaga tersebut. Maka LAZ harus terus berupaya untuk mempertahankan para muzakki yang telah mereka miliki sehingga akan terbentuk loyalitas muzakki. 
Indri, Asma: Pengaruh Kepuasan Muzakki...

Penilaian muzakki terhadap Lembaga Amil Zakat begitu beragam, sesuai dengan persepsi dan pengalaman masing-masing muzakki. Salah satu alasan seorang muslim membayar zakatnya melalui Lembaga Amil Zakat disebabkan karna faktor kepuasan (Firdaus, Beik, Irawan, Juanda, 2012). Salah satu faktor yang menentukan tingkat kepuasan adalah kualitas pelayanan (BAZNAS \& FEM IPB, 2011).

Kepuasan muzakki merupakan salah satu kunci dalam menciptakan loyalitas muzakki. Dalam membentuk kepuasan, LAZ perlu meningkatkan kualitas pelayanannya kepada muzakki. Pelayanan yang baik yang diberikan oleh LAZ akan membentuk persepsi dan harapan yang positif pada muzakki sehingga muzakki akan merasa puas dengan LAZ tersebut. Kualitas pelayanan yang baik ini membuat muzakki puas, karena harapan serta kebutuhan mereka telah terpenuhi.

Selain peningkatan kepuasan muzakki, Lembaga Amil Zakat juga harus memerhatikan prinsip lainnya yaitu transparansi dan akuntabilitas. Badan pengelola zakat termasuk Lembaga Amil Zakat dianggap tidak profesional karena belum menerapkan prinsip akuntabilitas dan transparansi (Sri Fadilah, 2012), maka untuk mempertahankan muzakki yang telah dimiliki oleh Lembaga Amil Zakat, LAZ harus meningkatkan profesionalitasnya dalam mengelola dana zakat. Peningkatan transparansi dan akuntabilitas LAZ dapat membuat muzakki semakin yakin untuk menyalurkan dana zakatnya kepada Lembaga Amil Zakat tersebut.

Lembaga Amil Zakat sebagai organisasi yang mengelola dana publik harus melaporkan hasil pengelolaan zakatnya. Pelaporan sumber daya secara publik merupakan pemenuhan tuntutan tata kelola masa kini yang terkait dengan penegakan good governance. Pengelolaan apapun jika berhubungan dengan pemanfaatan sumber daya publik, harus dikelola secara transparan dan akuntabel. Pelaporan hasil pengelolaan zakat ini merupakan pelaporan atas seluruh kegiatan yang meliputi perencanaan, pelaksanaan, penatausahaan, keuangan, pertanggungjawaban, dan pengawasan keuangan pengelolaan zakat. Oleh sebab itu, pengelolaan zakat harus dilakukan dengan tertib, taat pada peraturan perundangundangan, efektif, efisien, ekonomis dan bertanggungjawab agar pelaporannya dapat dibuat secara akuntabel dan transparan (Kementerian RI, 2013).

Jika LAZ mampu menyajikan pelaporan yang akuntabel dan transparan, dapat dipastikan publik akan puas dan semakin yakin untuk menyalurkan dana zakatnya 
Islamiconomic: Jurnal Ekonomi Islam Vol.7 No.2 Juli - Desember 2016

melalui Lembaga Amil Zakat (Kementerian Agama RI, 2013). Berdasarkan penelitian Jumaizi dan Wijaya (2011) pada BAZIS Jawa Tengah, terdapat pengaruh yang signifikan antara akuntabilitas, transparansi dan manfaat BAZIS terhadap kepuasan dan loyalitas muzakki.

Perbedaan penelitian ini dengan beberapa penelitian sebelumnya yaitu penelitian ini dilakukan pada LAZ Rumah Zakat, dimana LAZ tersebut merupakan salah satu LAZ terbesar di Indonesia dengan jumlah donatur pada tahun 2014 sebanyak 156.858 orang. Pada tahun 2014, LAZ Rumah Zakat telah menghimpun dana zakat sebesar Rp 79.961.568.561. Selain itu, laporan keuangan tahun 2014 yang diterbitkan oleh LAZ Rumah Zakat telah diaudit oleh KAP.Kanaka Puradireja Suhartono dengan opini wajar tanpa pengecualian.

Berdasarkan uraian di atas, maka diperlukan penelitian mengenai kepuasan muzakki, transparansi dan akuntabilitas pada Lembaga Amil Zakat untuk meningkatkan loyalitas muzakki sehingga setiap LAZ dapat meningkatkan penghimpunan dana zakatnya yang akan berpengaruh pada peningkatan penerimaan zakat secara nasional.

\section{Kajian Literatur}

\section{Zakat}

Kata zakat jika ditinjau dari segi bahasa merupakan kata dasar dari zaka yang memiliki arti berkah, tumbuh, bersih dan baik.Sedangkan secara terminologis, zakat adalah sejumlah harta tertentu yang diwajibkan Allah diserahkan kepada orangorang yang berhak. Zakat merupakan rukun Islam yang ketiga (Qardawi, 2006).

Definisi zakat juga dijelaskan di dalam Undang-Undang Nomor 23 Tahun 2011 Tentang Pengelolaan Zakat, dimana dalam undang-undang tersebut menyatakan bahwa zakat adalah harta yang wajib dikeluarkan oleh seorang muslim atau badan usaha untuk diberikan kepada yang berhak menerimanya sesuai dengan syariat Islam.

\section{Lembaga Amil Zakat}

Organisasi pengelola zakat yang dijelaskan di dalam Undang-Undang Nomor 23 Tahun 2011, adalah BAZNAS dan LAZ. BAZNAS atau Badan Amil Zakat Nasional 
Indri, Asma: Pengaruh Kepuasan Muzakki...

$\overline{\text { adalah lembaga yang melakukan pengelolaan zakat secara nasional. Sedangkan LAZ }}$ atau Lembaga Amil Zakat adalah lembaga yang dibentuk masyarakat yang memiliki tugas membantu pengumpulan, pendistribusian dan pendayagunaan zakat.

\section{Kepuasan}

Payandani (dalam Kabiri dkk, 2013) menyatakan bahwa yang dikatakan kepuasan adalah ketika seseorang merasa senang atas hasil yang memuaskan karena telah tercapai tujuan dan keinginanya.Sedangkan menurut Khirallah (dalam Pribanus Wantara, 2015) kepuasan merupakan sebuah persepsi dimana kebutuhan, harapan dan ekspektasi seseorang terhadap suatu produk atau pelayanan telah terpenuhi.

\section{Transparansi}

Menurut KNKG (2006), transparansi merupakan kondisi dimana lembaga menyediakan informasi yang material dan relevan dengan cara yang mudah diakses dan dipahami oleh pemangku kepentingan. Sedangkan menurut NCG (dalam Sri Fadilah, 2012), para pengelola wajib menjalankan prinsip keterbukaan dalam proses keputusan dan dalam menyampaikan informasi. Keterbukaan dalam menyampaikan informasi maksudnya adalah bahwa informasi yang disampaikan harus lengkap, benar dan tepat waktu kepada semua pihak pemangku kepentingan.

\section{Akuntabilitas}

Menurut NCG (National Committee on Governance) (dalam Sri Fadilah, 2012), prinsip akuntabilitas adalah prinsip bahwa para pengelola berkewajiban untuk membina sistem akuntansi yang efektif dalam rangka untuk menghasilkan laporan keuangan yanng dapat dipercaya. Selain itu, akuntabilitas juga mengandung unsur kejelasan fungsi dalam organisasi dan cara mempertanggungjawabkannya (www.ksap.org).

\section{Loyalitas}

Menurut Griffin (2003), loyalitas lebih ditujukan kepada suatu perilaku, yang ditujukan dengan pembelian rutin, didasarkan pada unit pengambilan keputusan. Ia 
Islamiconomic: Jurnal Ekonomi Islam Vol.7 No.2 Juli - Desember 2016

juga mengatakan bahwa loyalitas menunjukkan kondisi dari durasi waktu tertentu dan mensyaratkan bahwa tindakan pembelian tidak terjadi kurang dari dua kali.

Menurut Pearson (dalam Pribanus Wantara, 2015) loyalitas merupakan sikap atau perilaku seorang konsumen yang menguntungkan perusahaan, seperti melakukan pembelian ulang terhadap produk atau jasa perusahaan dan merekomendasikan produk dan jasa tersebut kepada orang lain.

\section{Metode Penelitian}

Populasi dalam penelitian ini adalah seluruh muzakki pada LAZ Rumah Zakat. Hingga akhir tahun 2014, jumlah donatur yang terdaftar pada LAZ Rumah Zakat sebanyak 156.858 orang.Teknik pengambilan sampel yang digunakan dalam penelitian kali ini adalah nonpropability sampling, yaitu teknik pengambilan sampel yang tidak memberi peluang yang sama bagi setiap anggota populasi untuk menjadi sampel. Secara lebih rinci, teknik yang digunakan adalah accindental sampling. Accidental sampling adalah teknik penentuan sampel berdasarkan kebetulan, yaitu siapa saja yang secara kebetulan/insidental bertemu dengan peneliti dapat digunakan sebagai sampel, bila dipandang orang yang kebetulan ditemui itu cocok sebagai sumber data (Sugiyono, 2011).

Kriteria muzakki yang dijadikan responden dalam penelitian ini adalah muzakki yang membayarkan zakatnya melalui LAZ Rumah Zakat. Sedangkan jumlah sampel dalam penelitian ini adalah 51 orang muzakki. Menurut Roscoe (dalam Sekaran, 2006) ukuran sampel $>30$ dan $<500$ adalah tepat untuk kebanyakan penelitian.

Sementara untuk teknik pengumpulan data yang digunakan dalam penelitian ini adalah kuesioner yang dilakukan dengan menyebarkan daftar pertanyaan kepada para responden. Kuesioner dibuat dalam bentuk pilihan ganda dengan lima butir opsi jawaban untuk setiap pertanyaan serta beberapa pertanyaan terbuka. Skala pengukuran yang digunakan adalah skala pengukuran Likert dimana skor 5 merupakan nilai tertinggi dan skor 1 merupakan nilai terendah. 
Indri, Asma: Pengaruh Kepuasan Muzakki...

Operasionalisasi Variabel

Tabel 1. Definisi Operasional Variabel

\begin{tabular}{|c|c|}
\hline Variabel & Indikator \\
\hline $\begin{array}{l}\text { Variabel } \\
\text { independen } \\
\text { Kepuasan }\left(\mathrm{X}_{1}\right)\end{array}$ & $\begin{array}{l}\text { 1. Kualitas jasa yang ditawarkan oleh Lembaga Amil Zakat } \\
\text { sesuai dengan kebutuhan muzakki. } \\
\text { 2. Program yang dibuat oleh Lembaga Amil Zakat sesuai } \\
\text { dengan harapan dan keinginan muzakki. } \\
\text { 3. Pelayanan secara keseluruhan yang diberikan oleh } \\
\text { Lembaga Amil Zakat baik dan memuaskan } \\
\text { 4. Lembaga Amil Zakat memberikan akses yang mudah bagi } \\
\text { muzakki untuk membayar zakat }\end{array}$ \\
\hline $\begin{array}{l}\text { Variabel } \\
\text { independen } \\
\text { Transparansi }\left(\mathrm{X}_{2}\right)\end{array}$ & $\begin{array}{l}\text { 1. Lembaga Amil Zakat menyediakan segala informasi yang } \\
\text { dibutuhkan secara tepat waktu, memadai, jelas, akurat dan } \\
\text { mudah diakses oleh pihak-pihak yang berkepentingan } \\
\text { termasuk muzakki LAZ dan publik. } \\
\text { 2. Lembaga Amil Zakat menyediakan informasi yang mudah } \\
\text { diakses dan dipahami oleh masyarakat secara luas. } \\
\text { 3. Lembaga Amil Zakat menyediakan informasi terkait } \\
\text { pengelolaan zakat mulai dari penghimpunan dana zakat } \\
\text { hingga pendistribusiannya. } \\
\text { 4. Lembaga Amil Zakat menyediakan informasi mengenai } \\
\text { kebijakan yang diterapkan di dalam lembaganya secara } \\
\text { tertulis dan dikomunikasikan kepada pemangku } \\
\text { kepentingan. }\end{array}$ \\
\hline $\begin{array}{l}\text { Variabel } \\
\text { independen } \\
\text { Akuntabilitas }\left(\mathrm{X}_{3}\right)\end{array}$ & $\begin{array}{l}\text { 1. Lembaga Amil Zakat menetapkan rincian fungsi, tugas dan } \\
\text { tanggung jawab masing-masing bagian yang terdapat di } \\
\text { dalam lembaga tersebut. } \\
\text { 2. Setiap bagian di dalam Lembaga Amil Zakat melaksanakan } \\
\text { tugasnya secara jujur. } \\
\text { 3. Lembaga Amil Zakat memiliki ukuran kinerja yang jelas. }\end{array}$ \\
\hline
\end{tabular}


Islamiconomic: Jurnal Ekonomi Islam Vol.7 No.2 Juli - Desember 2016

\begin{tabular}{|c|c|}
\hline & $\begin{array}{l}\text { 4. Lembaga Amil Zakat memiliki sistem penghargaan dan } \\
\text { sanksi (reward and punishment system). } \\
\text { 5. Lembaga Amil Zakat mengevaluasi pencapaian kinerjanya } \\
\text { secara berkala. } \\
\text { 6. Lembaga Amil Zakat memiliki tata cara pengelolaan } \\
\text { keluhan dan pengaduan } \\
\text { 7. Laporan pertanggungjawaban } \\
\text { disampaikan secara berkala sesuai dengan aturan yang } \\
\text { berlaku. } \\
\text { 8. Laporan pertanggungjawaban telah diaudit syariah dan } \\
\text { keuangan oleh lembaga yang berwenang }\end{array}$ \\
\hline $\begin{array}{l}\text { Variabel } \\
\text { dependen } \\
\text { Loyalitas (Y) }\end{array}$ & $\begin{array}{ll}\text { 1. } & \text { Hubungan antara Lembaga Amil Zakat dan muzakki telah } \\
& \text { terjalin kuat dan dalam jangka waktu yang lama } \\
\text { 2. } & \text { Muzakki melakukan pembayaran zakat secara rutin kepada } \\
& \text { Lembaga Amil Zakat } \\
\text { 3. } & \text { Muzakki telah dan akan merekomendasikan Lembaga Amil } \\
& \text { Zakat tersebut kepada orang lain } \\
\text { 4. } & \text { Muzakki tidak tertarik dengan penawaran produk-produk } \\
& \text { pembayaran zakat dari Lembaga Amil Zakat lain }\end{array}$ \\
\hline
\end{tabular}

\section{Hasil Dan Pembahasan}

a. Pengaruh Kepuasan Muzakki Terhadap Loyalitas Muzakki LAZ Rumah Zakat

Berdasarkan hasil pengujian, didapatkan hasil bahwa kepuasan muzakki berpengaruh signifikan terhadap loyalitas muzakki. Hasil analisis regresi yang dilakukan memperoleh nilai beta transparansi sebesar 0,363 dan nilai signifikansi lebih kecil dari 0,05 $(0,012<0,05)$. Hal ini mengindikasikan bahwa kepuasan muzakki pada LAZ Rumah Zakat berpengaruh signfikan terhadap loyalitas muzakki LAZ tersebut dengan arah koefisien positif.

Hasil penelitian ini mendukung penelitian dari Pribanus Wantara (2015) yang menyebutkan bahwa kepuasan memiliki pengaruh yang positif dan signifikan terhadap loyalitas.Kepuasan muzakki ini sangat penting bagi setiap 
Indri, Asma: Pengaruh Kepuasan Muzakki...

lembaga amil zakat untuk menciptkan loyalitas muzakki itu sendiri. Terdapat beberapa faktor yang dapat memengaruhi kepuasan muzakki di antaranya yaitu kualitas jasa dan pelayanan yang baik dan kemudahan yang diberikan oleh LAZ.

Sebagian besar responden telah merasa puas dengan pelayanan yang diberikan oleh LAZ Rumah Zakat, baik itu melalui pelayanan yang baik dan juga kemudahan dalam transaksi pembayaran zakat. Hal tersebut menjadi salah satu faktor loyalnya muzakki LAZ Rumah Zakat.

\section{b. Pengaruh Transparansi Terhadap Loyalitas Muzakki LAZ Rumah Zakat}

Berdasarkan hasil pengujian, didapatkan hasil bahwa transparansi berpengaruh signifikan terhadap loyalitas muzakki. Hasil analisis regresi yang dilakukan memperoleh nilai beta transparansi sebesar 0,265 dan nilai signifikansi lebih kecil dari 0,05 $(0,009<0,05)$. Hal ini mengindikasikan bahwa transparansi LAZ Rumah Zakat berpengaruh signfikan terhadap loyalitas muzakki LAZ tersebut dengan arah koefisien positif.

Hasil penelitian ini mendukung penelitian dari Jumaizi dan Zainal A. Wijaya (2011) yang menyebutkan bahwa terdapat pengaruh yang signifikan antara transparansi dengan loyalitas muzakki. Dalam konteks pengelolaan zakat, prinsip transparansi yang dimaksud adalah keterbukaan informasi yang berkaitan dengan pengelolaan zakat itu sendiri. Hal ini sangat penting dilakukan oleh lembaga pengelola zakat karena aktivitas utama yang dilakukan oleh lembaga-lembaga tersebut adalah menjalankan amanah publik dalam pengelolaan dana umat.

Transparansi yang dilakukan oleh LAZ Rumah Zakat di antaranya dengan cara mempublikasikan semua laporannya yang meliputi kegiatan, program hingga keuangan baik itu dimuat dalam website ataupun dimuat dalam majalah yang kemudian didistibusikan kepada para muzakkinya. Hal tersebut menjadi salah satu bukti bahwa LAZ Rumah Zakat telah menjalankan prinsip transparansi lembaga dengan sangat baik. 
Islamiconomic: Jurnal Ekonomi Islam Vol.7 No.2 Juli - Desember 2016

\section{c. Pengaruh Akuntabilitas Terhadap Loyalitas Muzakki LAZ Rumah Zakat}

Berdasarkan hasil pengujian, didapatkan hasil bahwa akuntabilitas berpengaruh tidak signifikan terhadap loyalitas muzakki. Hasil analisis regresi yang dilakukan memperoleh nilai beta akuntabilitas sebesar -0,056 dan nilai signifikansi lebih besar dari 0,05 $(0,307>0,05)$. Hal ini mengindikasikan bahwa akuntabilitas LAZ Rumah Zakat tidak berpengaruh signfikan terhadap loyalitas muzakki LAZ tersebut dengan arah koefisien negatif.

Hasil penelitian ini bertentangan dengan penelitian dari Jumaizi dan Zainal A. Wijaya (2011) yang menyebutkan bahwa terdapat pengaruh yang signifikan antara akuntabilitas dengan loyalitas muzakki. Hal ini dimungkinkan terjadi karena beberapa faktor yang timbul dari muzakki yang menjadi responden pada penelitian ini. Beberapa faktor yang memungkinkan menjadi penyebab di antaranya sebagai berikut :

1. Pertanyaan yang disampaikan oleh peneliti kurang mengarah kepada konsep akuntabilitas sehingga terjadi kerancuan pada responden dalam menjawab pertanyaan tersebut.

2. Adanya perbedaan pada objek penelitian dengan penelitian sebelumnya. Objek penelitian ini adalah muzakki LAZ Rumah Zakat, sedangkan objek penelitian yang dilakukan oleh Jumaizi dan Zainal A Wijaya (2011) adalah muzakki pada BAZIS Jawa Tengah.

3. Responden pada penelitian ini sudah tidak ragu lagi dengan akuntabilitas LAZ Rumah Zakat yang merupakan salah satu LAZ terbesar di Indonesia, dan atau responden lebih memerhatikan hal lain seperti program-program yang diselenggarakan oleh LAZ dan sebagainya.

Meskipun secara hasil statistik variabel akuntabilitas dinyatakan tidak berpengaruh terhadap loyalitas, setiap LAZ khususnya dalam hal ini adalah LAZ Rumah Zakat tetap harus menerapkan prinsip akuntabilitas dengan baik agar menghasilkan laporan yang berkualitas dan dapat dipercaya. Sebagaimana telah dipaparkan sebelumnya, bahwa ketiadaan pengaruh antara akuntabilitas dengan loyalitas ini bukan berarti menunjukkan tidak pentingnya prinsip akuntabilitas, namun dapat dimungkinkan bahwa para muzakki LAZ Rumah Zakat memang sudah tidak ragu lagi dengan akuntabilitas dari LAZ tersebut. 
Indri, Asma: Pengaruh Kepuasan Muzakki...

\section{Kesimpulan}

Berdasarkan hasil penelitian dan pembahasan, dapat ditarik kesimpulan sebagai berikut :

1. Secara simultan, kepuasan muzakki, transparansi dan akuntabilitas pada LAZ Rumah Zakat berpengaruh terhadap loyalitas muzakki LAZ Rumah Zakat.

2. Secara parsial, kepuasan muzakki berpengaruh positif terhadap loyalitas muzakki LAZ Rumah Zakat. Hal ini menujukkan bahwa semakin tinggi kepuasan muzakki maka akan semakin tinggi pula loyalitas muzakki.

3. Secara parsial, transparansi berpengaruh positif terhadap loyalitas muzakki LAZ Rumah Zakat. Hal ini menujukkan bahwa semakin tinggi transparansi maka akan semakin tinggi pula loyalitas muzakki.

4. Secara parsial, akuntabilitas tidak berpengaruh terhadap loyalitas muzakki LAZ Rumah Zakat.

\section{Saran}

Berdasarkan hasil penelitian dan pembahasan yang telah dijelaskan, pada bagian ini penulis bermaksud menyampaikan saran-saran yang diharapkan dapat berguna bagi pihak-pihak yang berkepentingan. Saran tersebut adalah sebagai berikut:

1. Saran untuk Lembaga Amil Zakat:

a. Akuntabilitas dan transparansi merupakan hal yang sangat penting sehingga harus diterapkan seluruhnya dengan baik oleh setiap Amil Zakat. Kedua konsep ini perlu diterapkan oleh seluruh lembaga publik, dalam hal ini khususnya yaitu Lembaga Amil Zakat sebagai wujud pertanggungjawaban atas pengelolaan dana umat tersebut.

b. Kepuasan muzakki harus menjadi salah satu fokus utama dari setiap Lembaga Amil Zakat. Kepuasan ini dapat diciptakan dengan pemberian pelayanan jasa dan pelayanan terbaik kepada setiap muzakki. Berdasarkan penelitian ini, kepuasan muzakki memiliki pengaruh yang signifikan terhadap loyalitas muzakki itu sendiri terhadap Lembaga Amil Zakat. Dalam jangka panjang, loyalitas muzakki ini dapat memberikan dampak yang positif 
Islamiconomic: Jurnal Ekonomi Islam Vol.7 No.2 Juli - Desember 2016

yaitu peningkatan penerimaan zakat pada LAZ yang bersangkutan sehingga dapat meningkatkan penerimaan zakat secara nasional.

2. Saran untuk Peneliti selanjutnya :

a. Agar hasil penelitian bisa lebih maksimal, jumlah muzakki yang menjadi responden diperbanyak.

b. Jika memungkinkan, waktu observasi penelitian sebaiknya diperpanjang.

c. Menambahkan variabel lain yang memungkinkan menjadi faktor yang dapat memengaruhi loyalitas muzakki

\section{Pustaka Acuan}

BAZNAS dan Fakultas Ekonomi dan Manajemen IPB.2011. Estimasi Potensi Zakat Nasional.Majalah SABILI No.24/XVIII.

Beik Firdaus, Irawan \& Juanda. 2012. Economic Estimation and Determinations of Zakat Potensial in Indonesia. IRTI Working Paper Series.

Griffin, Jill. 2003. Costumer Loyalty : Menumbuhkan \& Mempertahankan Kesetiaan Pelanggan. Jakarta. Erlangga.

Jumaizi \& Zainal A Wijaya. 2011. Good Governance Badan Amil Zakat, Infak dan Sedekah dan Dampaknyya Terhadap Keputusan dan Loyalitas Muzakki. Majalah Ilmiah Informatika Vol. 2 No. 3, September.

Kabiri, Fateme dkk. 2013. Effective Factors on Consumer Loyalty and Satisfaction. Kuwait Chapter of Arabian Journal of Business and Management Review Vol. 2, No.10; June.

Kementerian Agama RI. 2013. Standarisasi Amil Zakat di Indonesia. Jakarta. Direktorat Pemberdayaan Zakat.

Kementerian Agama. 2012. Laporan Tahunan Kehidupan Keagamaan di Indonesia 2012. Jakarta. Badan Litbang dan Diklat Puslitbang Kehidupan Keagamaan.

KNKG. 2006. Pedoman umum Good Corporate Governance. Jakarta. Komite Nasional Kebijakan Governance.

Majalah Zakat Edisi Mei-Juni 2013.Potensi Zakat Nasional. Hal 6. 
Indri, Asma: Pengaruh Kepuasan Muzakki...

Pribanus Wantara. 2015. The Relationships among Service Quality, Customer Satisfaction, and Customer Loyalty in Library Services. International Journal of Economics and Financial Issues, 5 (Special Issue) 264-269.

Qardawi, Yusuf. 2006. Hukum Zakat. Jakarta. Lintera Antar Nusa.

Sekaran, Uma. 2006. Metode Penelitian untuk Bisnisbuku 1 edisi 4. Jakarta. Salemba Empat. . 2006. Metode Penelitian untuk Bisnisbuku 2 edisi 4. Jakarta. Salemba Empat.

Sri Fadilah. 2012. Penerapan Good Fovernance Pada Lembaga Amil Zakat. Bandung. Unpad Press.

Sugiyono. 2011. Metode Penelitian Bisnis. Bandung. Alfabeta.

Undang-Undang Nomor 23 Tahun 2011 Tentang Pengelolaan Zakat. .http://www.ksap.org/sap/good-public-governance/\#Good_Public_Governance (diakses 7 Januari 2016). 
Islamiconomic: Jurnal Ekonomi Islam Vol.7 No.2 Juli - Desember 2016 